Published in final edited form as:

Epilepsia. 2019 March ; 60(3): 508-517. doi:10.1111/epi.14660.

\title{
Ventilatory response to $\mathrm{CO}_{2}$ in patients with epilepsy
}

\author{
Rup K. Sainju, MBBS ${ }^{1}$, Deidre N. Dragon, BSS ${ }^{1}$, Harold B. Winnike, RRT ${ }^{2}$, Marcus B. \\ Nashelsky, MD ${ }^{3}$, Mark A. Granner, MD1 , Brian K. Gehlbach, MD\#1,4, and George B. \\ Richerson, MD, PhD $\# 1,5,6$ \\ ${ }^{1}$ Department of Neurology, University of lowa Carver College of Medicine \\ ${ }^{2}$ Institute for Clinical and Translational Science, University of lowa Carver College of Medicine \\ ${ }^{3}$ Department of Pathology, University of lowa Carver College of Medicine \\ ${ }^{4}$ Department of Internal Medicine, University of lowa Carver College of Medicine \\ ${ }^{5}$ Department of Molecular Physiology and Biophysics, University of lowa Carver College of \\ Medicine \\ ${ }^{6}$ Veterans Affairs Medical Center, lowa City, IA \\ \# These authors contributed equally to this work.
}

\begin{abstract}
Objective: Severe peri-ictal respiratory depression is thought to be linked to SUDEP risk but its determinants are largely unknown. Inter-individual differences in the interictal ventilatory response to $\mathrm{CO}_{2}$ (hypercapnic ventilatory response [HCVR] or central respiratory $\mathrm{CO}_{2}$ chemosensitivity) may identify patients who are at increased risk for severe peri-ictal hypoventilation. HCVR has not been previously studied in patients with epilepsy; therefore, we evaluated a method to measure it at bedside in an epilepsy monitoring unit (EMU), and examined its relationship to postictal hypercapnia following generalized convulsive seizures (GCS).
\end{abstract}

Methods: Interictal HCVR was measured by a respiratory gas analyzer using a modified rebreathing technique. Minute ventilation $\left(\mathrm{V}_{\mathrm{E}}\right)$, tidal volume, respiratory rate, end tidal $(\mathrm{ET}) \mathrm{CO}_{2}$ and $\mathrm{O}_{2}$ were recorded continuously. Dyspnea during the test was assessed using a validated scale. The HCVR slope $\left(\Delta \mathrm{V}_{\mathrm{E}} / \Delta \mathrm{ETCO} \mathrm{C}_{2}\right)$, for each subject was determined by linear regression.

\footnotetext{
Corresponding author: Rup Sainju, MBBS, Department of Neurology, University of Iowa Carver College of Medicine, 200 Hawkins Drive, RCP-Neurology Clinic, Iowa city, Iowa 52242, USA, rup-sainju@ uiowa.edu, Telephone: 319-383-7767. Contributors:

Dr. Sainju: Acquisition of data, analysis and interpretation of data, drafting of manuscript

Ms. Dragon: Acquisition and interpretation of data, critical revision of manuscript

Mr. Winnike: Acquisition and interpretation of data, critical revision of manuscript

Dr. Nashelsky: Acquisition and interpretation of data, critical revision of manuscript

Dr. Granner: Interpretation of data, critical revision of manuscript

Dr. Richerson: Study concept and design, interpretation of data, critical revision of the manuscript

Dr. Gehlbach: Study concept and design, interpretation of data, critical revision of the manuscript

Competing interests:

R.K. Sainju, D.N. Dragon, H.B. Winnike, M.B. Nashelsky, M.A. Granner, G.B. Richerson and B.K. Gehlbach report no other disclosures relevant to the manuscript.

Patient Consent: Obtained

Ethics approval: University of Iowa Human Subjects office/Institutional review board (IRB)
} 
During the video EEG study, subjects underwent continuous respiratory monitoring, including measurement of chest and abdominal movement, oro-nasal airflow, transcutaneous (tc) $\mathrm{CO}_{2}$, and capillary oxygen saturation $\left(\mathrm{SPO}_{2}\right)$.

Results: Sixty-eight subjects completed HCVR testing in $151 \pm 58$ seconds, without any serious adverse events. HCVR slope ranged from -0.94 to 5.39 (median 1.71) $\mathrm{L} / \mathrm{min} / \mathrm{mm} \mathrm{Hg}$. HCVR slope correlated with the degree of unpleasantness and intensity of dyspnea, and was inversely related to baseline $\mathrm{ETCO}_{2}$. Both the duration and magnitude of postictal $\mathrm{tcCO}_{2}$ rise following GCS were inversely correlated with HCVR slope.

Significance: Measurement of the HCVR is well tolerated and can be performed rapidly and safely at the bedside in the EMU. A subset of individuals has a very low sensitivity to $\mathrm{CO}_{2}$ and this group is more likely to have a prolonged increase in postictal $\mathrm{CO}_{2}$ after GCS. Low interictal HCVR may increase the risk of severe respiratory depression and SUDEP after GCS and warrants further study.

\section{Keywords}

epilepsy; SUDEP; biomarker; central chemoresponsiveness; generalized tonic-clonic seizures; hypercapnia

\section{INTRODUCTION}

SUDEP is an important cause of mortality in patients with epilepsy ${ }^{1,2}$. Research conducted in a variety of animal models suggests that respiratory dysfunction following generalized convulsive seizures (GCSs, encompassing focal to bilateral tonic clonic and generalized tonic-clonic) may lie within the causal pathway of many SUDEP cases ${ }^{3,4}$, a hypothesis that is further supported by data from a limited number of SUDEP cases that have occurred in epilepsy monitoring units (EMUs) ${ }^{5}$. Peri-ictal hypoventilation, including central apnea, may occur in both focal seizures with impaired awareness and GCSs ${ }^{6,7}$, a process that may be mediated by seizure invasion of the amygdala ${ }^{8}$. The occurrence of frequent or severe periictal hypoventilation has been proposed as a biomarker of SUDEP risk ${ }^{6}$ but its determinants are largely unknown.

During steady-state wakeful conditions, ventilation is determined mostly by central chemosensitivity to $\mathrm{CO}_{2}{ }^{3,9,10}$, as well as by non-chemoreflex drives including cortical drive ${ }^{11}$, whereas central chemosensitivity to $\mathrm{CO}_{2}$ becomes an even more dominant source of respiratory drive during sleep ${ }^{12,13}$. After a GCS, hypercapnia and acidosis may occur ${ }^{14}$, and in some patients hypercapnia may be severe and prolonged, reflecting severe hypoventilation ${ }^{4,15}$ that implies reduced respiratory $\mathrm{CO}_{2}$ chemosensitivity.

Central respiratory $\mathrm{CO}_{2}$ chemosensitivity can be quantified using the hypercapnic ventilatory response $(\mathrm{HCVR})$, which measures the increase in minute ventilation $\left(\mathrm{V}_{\mathrm{E}}\right)$ induced by an increase in end tidal $\mathrm{CO}_{2}\left(\mathrm{ETCO}_{2}\right)^{16,17}$. We evaluated a method to measure the HCVR rapidly and conveniently at the bedside in a population of adult patients with epilepsy. We hypothesized that the test would be well tolerated in patients with epilepsy, and easily incorporated into the workflow of a busy EMU. We further hypothesized a wide range 
of sensitivity to $\mathrm{CO}_{2}$ in this population, and that a reduced HCVR would correlate with the severity of postictal hypoventilation after GCS.

\section{MATERIALS AND METHODS}

\section{Patients and clinical setting}

This is a prospective study that was approved by the Institutional Review Board at the University of Iowa. All subjects provided informed consent. Eligible subjects were 18 years or older with confirmed epilepsy who were undergoing video EEG monitoring in the EMU at the University of Iowa Hospitals and Clinics. Subjects were excluded if they had a history of active cardio-pulmonary disease or had a stroke or space occupying lesion in the brain. Patients were also excluded if there was a possibility of pregnancy based on the results of a screening questionnaire and/or a urine pregnancy test as appropriate.

All the subjects consented for long-term follow up by telephone every 6 months to assess their overall health status. The most recent neurology clinic visit was also reviewed for those subjects followed at the University of Iowa Hospitals and Clinics.

\section{Measurement of the HCVR:}

The HCVR test was performed at bedside in the EMU using a modified hyperoxic rebreathing technique ${ }^{16,17}$ and an Ultima PFX Respiratory Gas Analyzer (MGC Diagnostics, St. Paul Minnesota, USA). Inter-ictal testing was typically performed on Day 1 of EMU admission while still on home seizure medications. Subjects were seated comfortably facing a blank screen and wore noise cancelling headphones and a nasal clip. Each test began with measurement of baseline values for respiratory rate $(\mathrm{RR}), \mathrm{V}_{\mathrm{E}}$, tidal volume $\left(\mathrm{V}_{\mathrm{T}}\right), \mathrm{ETCO}_{2}$, and end-tidal oxygen $\left(\mathrm{ETO}_{2}\right)$ while breathing room air for 30-45 seconds. Then, the HCVR was measured by having subjects breathe through a Y-valve that allowed switching from room air to two 5-liter rebreathing bags pre-filled with 50\% oxygen, $6 \%$ carbon dioxide, and balance nitrogen. Subjects took two deep breaths to promote rapid equilibration of $\mathrm{CO}_{2}$ between the rebreathing bag and the alveolar, arterial and mixed venous compartments. They were then asked to breathe in whatever way they felt was most comfortable. The test was terminated for: (1) $\mathrm{ETCO}_{2}>55 \mathrm{~mm} \mathrm{Hg}$ (> $60 \mathrm{~mm} \mathrm{Hg}$ for subjects with baseline hypercapnia), (2) $\mathrm{ETO}_{2}<160 \mathrm{~mm} \mathrm{Hg}$; (3) $\mathrm{V}_{\mathrm{E}}>100$ liters/minute; or (4) subject intolerance. After the test, subjects completed the Multidimensional Dyspnea Profile $(\mathrm{MDP})^{18,19}$, a validated scale designed to assess the intensity (sensory component) and unpleasantness (affective component) of dyspnea, with each dimension rated on a scale from 0 to 10 (maximum intensity or unpleasantness).

As we gained confidence performing the procedure in this patient population we added a brief period of hyperventilation to a target $\mathrm{ETCO}_{2} \leq 30 \mathrm{~mm} \mathrm{Hg}$ or at least $10 \mathrm{~mm} \mathrm{Hg}$ below their baseline values prior to $\mathrm{CO}_{2}$ inhalation. This maneuver maximized the number of data points available for calculation of HCVR slope. This maneuver was not, however, long enough to allow for determination of the ventilatory recruitment threshold for $\mathrm{CO}_{2}$ - the $\mathrm{ETCO}_{2}$ below which ventilation is determined by waking neural drive ${ }^{16}$. 


\section{Continuous video EEG and comprehensive respiratory monitoring:}

The duration of video EEG monitoring for each patient was determined by the clinical team. EEG was recorded from scalp electrodes placed using the standard 10-20 system with addition of T1 \& T2 electrodes (Nihon Kohden, Japan). EKG was recorded using three leads placed at bilateral infraclavicular and suprascapular locations. Capillary oxygen saturation $\left(\mathrm{SpO}_{2}\right)$ and transcutaneous $\mathrm{CO}_{2}\left(\mathrm{tcCO}_{2}\right)$ were measured on the forehead or cheekbone, and both were recorded continuously (SenTec Digital Monitoring System, Therwil BL, Switzerland). The accuracy and reliability of $\mathrm{tcCO}_{2}$ monitoring have been previously established $^{20-21}$. Chest and abdominal belts were used to perform respiratory inductance plethysmography (Pro-Tech zRIP DuraBelt, Philips Respironics, Morrisville, PA). Airflow was measured using a nasal pressure transducer (BiNaps, Salter Labs, Arvin, CA) and an oro-nasal thermistor (ThermiSense, Salter Labs, Arvin, CA).

Both the video and EEG of each seizure were carefully reviewed by a board certified epileptologist (RKS) and respiratory data were reviewed by the same epileptologist as well as a board-certified pulmonologist (BKG). Clinical and EEG seizure onset as well as the duration of the convulsive phase were recorded for each seizure.

For each GCS, the baseline $\mathrm{tcCO}_{2}, \mathrm{SPO}_{2}$, heart rate, and respiratory rate were established by averaging data every 10 seconds from 2 minutes prior to electrographic seizure onset to one minute prior to electrographic seizure onset. The duration of post-ictal $t c \mathrm{CO}_{2}$ rise was defined as the time interval between (a) the point at which the $\mathrm{tcCO}_{2}$ increased by at least $10 \%$ over the pre-ictal baseline $\mathrm{tcCO}_{2}$ and (b) the point at which the $\mathrm{tcCO}_{2}$ fell (returned) to $<10 \%$ above the pre-ictal baseline. The magnitude of $\mathrm{tcCO}_{2}$ rise was expressed as $\Delta \mathrm{tcCO}_{2}$, which was calculated as the difference between the peak tcCO2 during the post-ictal state and the pre-ictal baseline tc $\mathrm{CO}_{2}$. Likewise, the duration of oxygen desaturation was defined as the time interval between (a) the point at which the $\mathrm{SPO}_{2}$ fell below $90 \%$ and (b) the point at which the $\mathrm{SPO}_{2}$ returned to $90 \%$ or greater. The nadir of $\mathrm{SPO}_{2}$ was also determined. Only GCS with interpretable tc $\mathrm{CO}_{2}$ data were considered for analysis in the study. When subjects had more than one GCS, the duration of post-ictal tcCO2 rise and $\Delta \mathrm{tcCO}_{2}$ were averaged.

\section{Clinical variables}

All subjects eligible for HCVR testing filled out questionnaires on their clinical history. Medical records were reviewed to collect additional information. Variables included for analysis were age, gender, duration of epilepsy, current antiepileptic drugs (AEDs), body mass index (BMI), history of depression, history of obstructive sleep apnea (OSA), active tobacco use, current use of serotonin selective reuptake inhibitors (SSRIs) or serotoninnorepinephrine reuptake inhibitors (SNRIs), and results of current and prior video-EEG monitoring.

\section{Statistics}

Calculation of HCVR slope $\left(\Delta \mathrm{V}_{\mathrm{E}} / \Delta \mathrm{ETCO}_{2}\right)$ : for each subject, the $\mathrm{V}_{\mathrm{E}} \mathrm{vs} \mathrm{ETCO}_{2}$ relationship was fit with a least squares regression (Figures $1 \mathrm{~A}, \mathrm{~B}$, and $\mathrm{C}$ ). During the HCVR testing, the $\mathrm{ETCO}_{2}$ tends to rise in most patients immediately after initial two breaths which is due to acute inhalation of $\mathrm{CO}_{2}$ rather than their chemoresponsiveness. Therefore, 
for least squares fits, we excluded all values up to and including the time that patients took two deep breaths. Graphing and regression analyses were performed using Prism 7 (GraphPad Software, La Jolla, CA).

SPSS software (IBM Analytics, Somers, NY) was used for statistical analyses. Spearman's rho correlation coefficient test (two tailed, alpha $=0.05$ ), was used for univariate analyses examining the relationship between clinical variables and HCVR slope (dependent variable). A similar approach was used to analyze the relationship between HCVR slope and the duration or magnitude $\left(\Delta \mathrm{tcCO}_{2}\right)$ of post-ictal $\mathrm{tcCO}_{2}$ rise. The Mann-Whitney $\mathrm{U}$ test was used to compare median values (two tailed, alpha $=0.05$ ).

\section{RESULTS}

\section{Subject characteristics}

Table 1 summarizes patient characteristics. A total of sixty-eight subjects were enrolled in the study with age ranging from 20 to 69 years. Most (86.6\%) subjects had focal epilepsy. At the time of admission to the EMU, three subjects were not taking any AEDs while 20 were on $1 \mathrm{AED}$ and the remaining subjects were on 2 or more AEDs.

\section{Measurement of the HCVR and tolerability of the HCVR}

The resting $\mathrm{ETCO}_{2}$ prior to measurement of the $\mathrm{HCVR}$ ranged from 25 to $45 \mathrm{~mm} \mathrm{Hg}$ with a mean of $37 \pm 4.2 \mathrm{~mm} \mathrm{Hg}$.

The HCVR was successfully measured in 67 subjects (a calibration error occurred during measurement in one patient, so it was excluded from further analysis). Fifty-eight patients reached the target $\mathrm{ETCO}_{2}$. Nine subjects stopped the test for various reasons at a final ETCO $_{2}$ of 49 to $54 \mathrm{~mm} \mathrm{Hg}$. Transient symptoms experienced by the subjects during the test are summarized in Table 2. All symptoms resolved rapidly upon return to room air breathing. There were no serious adverse events.

The mean duration of $\mathrm{CO}_{2}$ rebreathing during HCVR measurement was $151 \pm 58$ seconds. In 43 subjects we measured the time for the $\mathrm{ETCO}_{2}$ to normalize after completing the test. Subjects averaged $10 \pm 8$ seconds for their $\mathrm{ETCO}_{2}$ to return to their pre-testing baseline. Seventy-six percent of subjects overcorrected their $\mathrm{ETCO}_{2}$ by $\geq 3 \mathrm{~mm} \mathrm{Hg}$ below their baseline $\mathrm{ETCO}_{2}$. When compared with the remaining subjects, those who overcorrected their $\mathrm{ETCO}_{2}$ had a higher median HCVR slope (1.93 vs $1.25 \mathrm{~L} / \mathrm{min} / \mathrm{mm} \mathrm{Hg}, \mathrm{p}=0.006$ ).

\section{HCVR slope and its relationship with clinical variables}

HCVR slope varied from -0.94 to $5.39 \mathrm{~L} / \mathrm{min} / \mathrm{mm} \mathrm{Hg}$. The distribution of slopes appeared Gaussian (Figure 1 D) with a mean of $1.87 \pm 1.19$ and variance of $1.41 \mathrm{~L} / \mathrm{min} / \mathrm{mm} \mathrm{Hg}$. The median and inter quartile range (IQR) were 1.71 and $0.98 \mathrm{~L} / \mathrm{min} / \mathrm{mm} \mathrm{Hg}$, respectively.

The subjects' MDP scores for unpleasantness and intensity of dyspnea provoked by the rebreathing test were positively correlated with their HCVR slopes ( $\mathrm{rho}=0.434$ and 0.468 ; $\mathrm{p}=0.0003$ and 0.000085 ). In contrast, baseline $\mathrm{ETCO}_{2}$ was inversely correlated with HCVR slope ( $\mathrm{rho}=-0.267, \mathrm{p}=0.034)$. No significant correlation was found between HCVR slope 
and age, gender, duration of epilepsy, OSA, BMI, use of SSRI/SNRIs, or current smoking (Table 3A).

\section{Video EEG and peri-ictal respiratory monitoring}

A total of 49 GCSs (44 focal to bilateral tonic-clonic ) were recorded from 24 subjects. Thirteen GCSs from 11 subjects had sufficient data to calculate duration of post-ictal tcCO2 rise.

The mean duration of the convulsive phase was $64 \pm 22$ seconds, with a range of 39 to 115 seconds. All $13 \mathrm{GCSs}$ were associated with post-ictal tcCO $\mathrm{tcl}_{2}$ elevation and oxygen desaturation of varying severity. The duration of post-ictal $\mathrm{tcCO}_{2}$ rise ranged from 134 seconds to 756 seconds, with a mean of $433 \pm 229$ seconds. Peak $\mathrm{tcCO}_{2}$ value ranged from 45 to $75 \mathrm{~mm} \mathrm{Hg}$ with a mean $\Delta \mathrm{tcCO}_{2}$ (increase from baseline) of $18.1 \pm 6 \mathrm{~mm} \mathrm{Hg}$. Likewise, duration of oxygen desaturation ranged from 34 seconds to 238 seconds with a mean of $104 \pm 77$ seconds. Nadir $\mathrm{SPO}_{2}$ ranged from $14 \%$ to $79 \%$, with a mean of $53.0 \%$ $\pm 21.8 \%$.

Univariate analyses examining the relationship between HCVR slope and selected clinical variables and the duration and magnitude $\left(\Delta \mathrm{tcCO}_{2}\right)$ of post-ictal tcCO $\mathrm{CO}_{2}$ elevation are summarized in Table 3B. HCVR slope was inversely correlated with both the duration and magnitude of $\mathrm{tcCO}_{2}$ elevation in the post-ictal state $(\mathrm{rho}=-0.745$ and $-0.778 ; \mathrm{p}=0.008$ and 0.014; Figure 2). Duration and magnitude of $\mathrm{tcCO}_{2}$ rise were also correlated with each other $(\mathrm{rho}=0.770, \mathrm{p}=0.015)$. There was no significant relationship between HCVR slope and BMI, OSA, duration of convulsion, duration of peri-ictal $\mathrm{O}_{2}$ desaturation, or nadir of periictal $\mathrm{O}_{2}$ desaturation.

\section{Long-term follow up:}

At the time of this manuscript preparation, 55 subjects had completed at least six months of follow up, 43 patients had one year follow up, and 12 patients had two years of follow up. One patient was lost to follow up. All 55 subjects were ascertained to be alive at six months. However, one subject with pharmaco-resistant focal epilepsy died of "SUDEP plus"22" 11 months after being studied. This subject was a 52-year-old man with pharmaco-resistant focal epilepsy. His medical problems consisted of hypertension, viral encephalitis in 1996, and a remote history of alcohol abuse and depression. He had his first seizure during the time of his acute viral encephalitis, and subsequently continued to have an average of 2-3 convulsive seizures per month despite multiple AED trials. At the time of enrollment, he had a markedly blunted HCVR slope $(0.19 \mathrm{~L} / \mathrm{min} / \mathrm{mm} \mathrm{Hg}$, Figure 1D). Approximately 36 hours after HCVR testing, his video EEG study captured one focal to bilateral tonic-clonic seizure, with a convulsive phase lasting 66 seconds. He also experienced significant oxygen desaturation, with an $\mathrm{SPO}_{2}$ nadir of $61 \%$ and a total duration of desaturation of 240 seconds (Figure 3). Unfortunately, the magnitude and duration of post ictal $\mathrm{tcCO}_{2}$ rise were not able to be measured due to signal loss.

He was discharged from the hospital with the addition of a new AED, lamotrigine. Three months later, he was admitted to the hospital for acute pancreatitis potentially related to lamotrigine, so it was switched to oxcarbazepine. He subsequently developed a pseudo 
pancreatic cyst, which was treated with antibiotics and placement of a drain. Despite these setbacks he had a full recovery and returned home in his baseline medical condition. One morning approximately 5 months later (11 months from this video EEG study), he was found dead, lying in the prone position in bed. A full autopsy examination revealed a flaccid heart with four chamber dilatation, consistent with a dilated cardiomyopathy, along with bilateral pulmonary congestion and congestive hepato-splenomegaly. Toxicologic examination of the blood showed no evidence of a drug or ethanol contribution to death. The patient did not have any antemortem complaints of cardiac illness and did not exhibit prior signs of a dilated cardiomyopathy. The findings and circumstances of his death, are consistent with "SUDEP plus"22.

\section{DISCUSSION}

We demonstrate here the successful bedside measurement of the interictal HCVR in patients with epilepsy, and its relationship to the duration and magnitude of $\mathrm{tcCO}_{2}$ rise after GCS. To our knowledge, this is the first such study of the HCVR in this population. Our main findings include:

1. Measurement of the HCVR was rapid, safe, and generally well tolerated by the participants. Indeed, the test was simple enough that it could be administered in an outpatient setting.

2. Subjects showed a wide range of ventilatory responses.

3. HCVR slope was positively correlated with the dyspnea rating scale for unpleasantness and intensity.

4. $\mathrm{HCVR}$ slope was inversely correlated with baseline $\mathrm{ETCO}_{2}$, consistent with an effect of blunted $\mathrm{CO}_{2}$ chemosensitivity on baseline ventilation.

5. Both the duration and magnitude of post-ictal $\mathrm{tcCO}_{2}$ rise after GCS were inversely correlated with HCVR slope.

6. One subject with pharmaco-resistant epilepsy and a markedly blunted HCVR slope died of "SUDEP plus" 11 months after being studied.

The relationship between $\mathrm{ETCO}_{2}$ and VE during the HCVR is approximately linear over a wide range (30-100 $\mathrm{mm} \mathrm{Hg}$ of $\left.\mathrm{ETCO}_{2}\right)^{23}$. Hyperventilation is a potential trigger for seizures in some patients with epilepsy, and high $\mathrm{ETCO}_{2}$ can potentially trigger discomfort and anxiety. Therefore, out of an abundance of caution, we employed a more modest period of hyperventilation than that described by Mohan and Duffy ${ }^{16}$, but still one that changed $\mathrm{CO}_{2}$ over the linear range. We also selected a lower target $\mathrm{CO}_{2}(55 \mathrm{vs} 60 \mathrm{~mm} \mathrm{Hg})$ for test termination than the target utilized in some studies.

The ventilatory response to $\mathrm{CO}_{2}$ (HCVR slope) among patients with epilepsy varied widely. This variability was in line with previous studies performed in healthy adults ${ }^{24}$. However, the lowest response we recorded $(-.94 \mathrm{~L} / \mathrm{min} / \mathrm{mm} \mathrm{Hg})$ is lower than previously reported $(0.4$ $\mathrm{L} / \mathrm{min} / \mathrm{mm} \mathrm{Hg}$ ) for normal adults ${ }^{24}$. The reason for this subject's negative HCVR is unclear, but may be due to cortical influences on breathing. We took steps to minimize these influences by following a standard testing procedure, and by asking our subjects to use noise 
canceling headphones and to focus on a blank screen during the test. It is likely that the steps we took reduced variability due to cortical influences to only a modest level, but that they did not entirely eliminate it. We did not find any significant correlation between HCVR slope and age, gender, or OSA as previously reported ${ }^{25-28}$.

Although the ventilatory response to $\mathrm{CO}_{2}$ may be modulated by environmental and acquired factors, genetic factors are likely to have a dominant influence. A study comparing monozygotic to dizygotic twins suggested genetic factors determine the sensitivity of central chemoreceptors $^{29}$. Teenage swimmers and their siblings have a similar HCVR slope, regardless of whether the siblings are also swimmers ${ }^{26}$. Similarly, a study described familial clusters of low ventilatory response to $\mathrm{CO}_{2}$ in a study of the Egna people of New Guinea ${ }^{30}$. However, we cannot rule out the possibility that there are some individuals with a low HCVR due to acquired causes, such as infection or prior neurological insult.

An inverse relationship between $\mathrm{HCVR}$ slope and baseline $\mathrm{ETCO}_{2}$, as reported here, has been previously reported in patients with sleep apnea syndrome ${ }^{31}$. Individuals with a high level of chemosensitivity (large HCVR slope) respond to a small increase in $\mathrm{ETCO}_{2}$ with a large increase in minute ventilation. This is expected to maintain a relatively low level of $\mathrm{CO}_{2}$ at baseline, which is what we found. During the recovery phase after rebreathing $\mathrm{CO}_{2}$, subjects who over corrected their ETCO 2 by $\geq 3 \mathrm{~mm} \mathrm{Hg}$ had a higher HCVR slope than those who did not, again suggesting that highly responsive central chemoreceptors maintain lower $\mathrm{CO}_{2}$ levels.

We found that both the intensity and unpleasantness of dyspnea correlated with HCVR slope in this study. This indicates that individuals with low $\mathrm{CO}_{2}$ chemosensitivity not only have a reduced ventilatory response to $\mathrm{CO}_{2}$, but they also have less dyspnea when hypercapnic. It is thought that a low $\mathrm{CO}_{2}$ chemosensitivity may be an advantage for athletes who participate in endurance events like swimming or running ${ }^{26,32}$. In other circumstances, however, a low chemosensitivity contributes to disease, as in the obesity hypoventilation syndrome, or may even be life threatening, as in congenital central hypoventilation syndrome ${ }^{33}$.

$\mathrm{TcCO}_{2}$ rose by at least $10 \%$ after GCS in all cases for which these data were available. Although postictal apnea occurs after convulsive seizures ${ }^{34}$, our findings suggest that GCS can also provoke a more subtle form of hypoventilation: namely, ventilation that is not frankly apneic or bradypneic, but is insufficient to meet the metabolic demands of a convulsive seizure ${ }^{14}$. We did not find any significant association between either the duration or magnitude of post-ictal tcCO $\mathrm{CO}_{2}$ rise and the duration of convulsive phase of the seizure, similar to the findings of Seyal et al ${ }^{15}$.

Despite a limited number of GCS available for analysis, our findings clearly suggest that the severity of postictal respiratory depression following GCS is strongly influenced by baseline $\mathrm{CO}_{2}$ chemosensitivity, as indicated by the inverse correlation between HCVR slope and the duration and magnitude of post-ictal $\mathrm{tcCO}_{2}$ rise. Therefore, interictal measurement of HCVR could serve as a surrogate for severity of post-ictal hypoventilation, a hypothesis that should be tested in a larger study. If true, interictal HCVR could be measured much more easily, including in the outpatient clinic, than post-ictal $\mathrm{tcCO}_{2}$, which requires an EMU admission. 
We hypothesize that an inadequate ventilatory response to $\mathrm{CO}_{2}$ in patients with a low $\mathrm{HCVR}$ slope may contribute to a potentially life-threatening situation when the patient's airway and consciousness are both compromised; e.g. an unattended patient with decreased level of arousal in the prone position after a GCS. If this is the case, low $\mathrm{CO}_{2}$ chemosensitivity would not be the "cause" of SUDEP, but rather would confer vulnerability in a context where the body's homeostasis is challenged. We speculate that low $\mathrm{CO}_{2}$ chemosensitivity may have contributed to the sudden death of our subject who had an unusually low HCVR slope and died of SUDEP plus. While drawing conclusions from a single case would be premature, further investigation of this hypothesis is warranted.

Serotonergic neurons in the raphe nuclei of the brainstem are known to play an important role in central $\mathrm{CO}_{2}$ chemoreception and $\mathrm{CO}_{2}$ induced arousal ${ }^{10,35}$. Pharmacologic manipulation to enhance central chemoreceptor sensitivity has been successfully demonstrated in animal studies using SSRIs ${ }^{36,37}$, and SSRIs protect against postictal respiratory arrest in DBA/2 mice ${ }^{38}$. In addition, in a study of epilepsy patients undergoing video-EEG monitoring, SSRIs were associated with reduced severity of ictal hypoxemia ${ }^{39}$. We did not find any correlation betwen SSRI/SNRI use and HCVR slope in our study. This may be due to the small sample size as this study was not designed specifically to evaluate this relationship. It is also possible that out results are confunded by the fact that many patients had diseases for which SSRIs and SNRIs were prescribed. If HCVR slope proves to be a useful surrogate for severe post-ictal hypoventilation, further clinical studies to examine the effect of SSRIs on the HCVR in patients with epilepsy are justified.

There are several limitations to our study. First, although the HCVR measurements were performed by the same respiratory therapist using the same machine and in a similar physical environment, we were unable to control for several factors-for instance, sleep deprivation and caffeine intake- that may influence the response. Second, sensor dislodgment and signal dropout from convulsive activity limited the number of generalized convulsive seizures that could be correlated with the HCVR. Finally, because our study was performed in a single center, our results should be replicated in another environment.

\section{CONCLUSIONS}

In patients with epilepsy, interictal central respiratory chemosensitivity to $\mathrm{CO}_{2}$ can be measured rapidly and safely at the bedside. This interictal $\mathrm{CO}_{2}$ chemosensitivity, or HCVR, varies widely between patients with epilepsy as predicted. Individuals with a low HCVR exhibit less dyspnea during testing and more severe respiratory depression following GCS. The method described here can be used to assay $\mathrm{CO}_{2}$ chemosensitivity in a variety of clinical contexts and under different experimental conditions, including in an outpatient clinic setting. The results of these studies may aid in identifying biomarkers for patients at the highest risk of SUDEP while providing new insights into the mechanisms responsible for peri-ictal respiratory depression.

\section{Acknowledgement:}

We would like to acknowledge all our EEG technologists, including lead technologist Ms. Deanne Tadlock, and all the EMU nurses for their continued assistance and support in completion of this study. 
We confirm that we have read the Journal's position on issues involved in ethical publication and affirm that this report is consistent with those guidelines.

Funding:

This study was supported by the National Institute of Neurologic Disorders and Stroke: U01 NS090414 (Center for SUDEP Research), Citizens United for Research in Epilepsy (CURE) - SUDEP award, and National Institute of Health CTSA program grant U54TR001356.

The Sentec Digital Monitoring System was provided by the company. The company was not involved in the design, execution, analysis, or reporting of this study.

\section{References:}

1. Thurman DJ, Hesdorffer DC, French JA. Sudden unexpected death in epilepsy: assessing the public health burden. Epilepsia. 2014;55:1479-1485. [PubMed: 24903551]

2. Sveinsson O, Andersson T, Carlsson S, et al. The incidence of SUDEP: A nationwide populationbased cohort study. Neurology. 2017;89:170-177. [PubMed: 28592455]

3. Massey CA, Sowers LP, Dlouhy BJ, et al. Mechanisms of sudden unexpected death in epilepsy: the pathway to prevention. Nat Rev Neurol. 2014;10:271-282. [PubMed: 24752120]

4. Kim Y, Bravo E, Thirnbeck CK, et al. Severe peri-ictal respiratory dysfunction is common in Dravet syndrome. J Clin Invest. 2018;128:1141-1153. [PubMed: 29329111]

5. Ryvlin P, Nashef L, Lhatoo SD, et al. Incidence and mechanisms of cardiorespiratory arrests in epilepsy monitoring units (MORTEMUS): a retrospective study. Lancet Neurol. 2013;12:966-977. [PubMed: 24012372]

6. Bateman LM, Li CS, Seyal M. Ictal hypoxemia in localization-related epilepsy: analysis of incidence, severity and risk factors. Brain. 2008;131:3239-3245. [PubMed: 18952672]

7. Moseley BD, Nickels K, Britton J, et al. How common is ictal hypoxemia and bradycardia in children with partial complex and generalized convulsive seizures? Epilepsia. 2010;51:1219-1224. [PubMed: 20067502]

8. Dlouhy BJ, Gehlbach BK, Kreple CJ, et al. Breathing Inhibited When Seizures Spread to the Amygdala and upon Amygdala Stimulation. J Neurosci. 2015;35:10281-10289. [PubMed: 26180203]

9. Richerson GB. Response to CO2 of neurons in the rostral ventral medulla in vitro. J Neurophysiol. 1995;73:933-944. [PubMed: 7608778]

10. Richerson GB. Serotonergic neurons as carbon dioxide sensors that maintain $\mathrm{pH}$ homeostasis. Nat Rev Neurosci. 2004;5:449-461. [PubMed: 15152195]

11. Horn EM, Waldrop TG. Suprapontine control of respiration. Respir Physiol. 1998;114:201-211. [PubMed: 9926985]

12. Kathe G, Hanke AA, James B, et al. Dempsey. Inhibition of Inspiratory Muscle Activity during Sleep: Chemical and Nonchemical influences.Am Rev Respir Dis. 1988;138:8-15. [PubMed: 3144204]

13. Skatrud JB and Dempsey JA. Interaction of sleep state and chemical stimuli in sustaining rhythmic ventilation. Jour ApplPhys. 1983;55:813-822.

14. Orringer CE, Eustace JC, Wunsch CD, et al. Natural history of lactic acidosis after grand-mal seizures. A model for the study of an anion-gap acidosis not associated with hyperkalemia. N Engl J Med. 1977;297:796-799. [PubMed: 19702]

15. Seyal M, Bateman LM, Alberston T, et al., . Respiratory changes with seizures in localizationrelated epilepsy: Analysis of periictal hypercapnia and airflow patterns. Epilepsia. 2010;51:13591364. [PubMed: 20163438]

16. Mohan R, Duffin J. The effect of hypoxia on the ventilatory response to carbon dioxide in man. Respir Physiol. 1997;108:101-115. [PubMed: 9232684]

17. Fan JL, Burgess KR, Basnyat R, et al. Influence of high altitude on cerebrovascular and ventilatory responsiveness to CO2. J Physiol. 2010;588:539-549. [PubMed: 20026618] 
18. Banzett RB, O'Donnell CR, Guilfoyle TE, et al. Multidimensional Dyspnea Profile: an instrument for clinical and laboratory research. Eur Respir J. 2015;45:1681-1691. [PubMed: 25792641]

19. Meek PM, Banzett R, Parsall MB, et al. Reliability and validity of the multidimensional dyspnea profile. Chest. 2012;141:1546-1553. [PubMed: 22267681]

20. Nassar BS, Schmidt GA. Estimating Arterial Partial Pressure of Carbon Dioxide in Ventilated Patients: How Valid Are Surrogate Measures? Ann Am Thorac Soc. 2017;14:1005-1014. [PubMed: 28570147]

21. Storre JH, Magnet FS, Dreher M, et al. Transcutaneous monitoring as a replacement for arterial PCO(2) monitoring during nocturnal non-invasive ventilation. Respir Med. 2011; 105:143-150. [PubMed: 21030230]

22. Nashef L, So EL, Ryvlin P, et al. Unifying the definitions of sudden unexpected death in epilepsy. Epilepsia. 2012;53:227-233. [PubMed: 22191982]

23. West JB. Best and Taylor's Physiological Basis of Medical 12th ed: Williams \& Wilkins, 1991.

24. Irsigler GB. Carbon dioxide response lines in young adults: the limits of the normal response. Am Rev Respir Dis. 1976;114:529-536. [PubMed: 970734]

25. Patrick JM, Howard A. The influence of age, sex, body size and lung size on the control and pattern of breathing during CO 2 inhalation in Caucasians. Respir Physiol. 1972;16:337-350. [PubMed: 4644060]

26. Saunders NA, Leeder SR, Rebuck AS. Ventilatory response to carbon dioxide in young athletes: a family study. Am Rev Respir Dis. 1976;113:497-502. [PubMed: 1267256]

27. Aitken ML, Franklin JL,Pierson DJ, et al. Influence of body size and gender on control of ventilation. J Appl Physiol. (1985) 1986;60:1894-1899. [PubMed: 3087935]

28. Sin DD, Jones RL, Man GC. Hypercapnic ventilatory response in patients with and without obstructive sleep apnea: do age, gender, obesity, and daytime $\mathrm{PaCO}(2)$ matter? Chest. 2000;117:454-459. [PubMed: 10669690]

29. Kawakami Y, Yamamoto H, Yoshikawa T, et al. Age-related variation of respiratory chemosensitivity in monozygotic twins. Am Rev Respir Dis. 1985;132:89-92. [PubMed: 4040345]

30. Beral V, Read DJ. Insensitivity of respiratory centre to carbon dioxide in the Enga people of New Guinea. Lancet. 1971;2:1290-1294. [PubMed: 4143540]

31. Garay SM, Rapoport D, Sorkin B,et al. Regulation of ventilation in the obstructive sleep apnea syndrome. Am Rev Respir Dis. 1981;124:451-457. [PubMed: 7294507]

32. Rebuck AS, Jones NL, Campbell EJ. Ventilatory response to exercise and to CO 2 rebreathing in normal subjects. Clin Sci. 1972;43:861-867. [PubMed: 4646278]

33. Weese-Mayer DE, Berry-Kravis EM, Ceccherini I, et al. An official ATS clinical policy statement: Congenital central hypoventilation syndrome: genetic basis, diagnosis, and management. Am J Respir Crit Care Med. 2010;181:626-644. [PubMed: 20208042]

34. Vilella L, Lacuey N, Hampson J, et al. Post-convulsive central apnea as a biomarker for Sudden Unexpected Death in Epilepsy (SUDEP).. Neurology. 2018 Available at: 10.1212/WNL. 0000000000006785 Accessed December 26, 2018.

35. Buchanan GF, Richerson GB. Central serotonin neurons are required for arousal to CO2. Proc Natl Acad Sci USA. 2010;107:16354-16359. [PubMed: 20805497]

36. Hodges MR, Echert AE, Puissant MM, et al. Fluoxetine augments ventilatory CO2 sensitivity in Brown Norway but not Sprague Dawley rats. Respir Physiol Neurobiol. 2013;186:221-228. [PubMed: 23454023]

37. Sahin G, Guner I, Yelmen N, et al. Alterations of central hypercapnic respiratory response induced by acute central administration of serotonin re-uptake inhibitor, fluoxetine. Chin J Physiol. 2011;54:356-366. [PubMed: 22135915]

38. Tupal S, Faingold CL. Evidence supporting a role of serotonin in modulation of sudden death induced by seizures in DBA/2 mice. Epilepsia. 2006;47:21-26.

39. Bateman LM, Li CS, Lin TC et al. Serotonin reuptake inhibitors are associated with reduced severity of ictal hypoxemia in medically refractory partial epilepsy. Epilepsia. 2010;51:2211-2214. [PubMed: 20491872] 


\section{Key Points}

- The ventilatory response to $\mathrm{CO}_{2}$ can be tested rapidly and safely at the bedside in patients with epilepsy.

- A subset of patients with epilepsy has a blunted hypercapnic ventilatory response.

- Interictal hypercapnic ventilatory response was inversely correlated with the severity of postictal hypercapnia after generalized convulsive seizures. 
A) Subject with median slope

Slope $=1.71 \mathrm{~L} / \mathrm{min} / \mathrm{mm} \mathrm{Hg}$

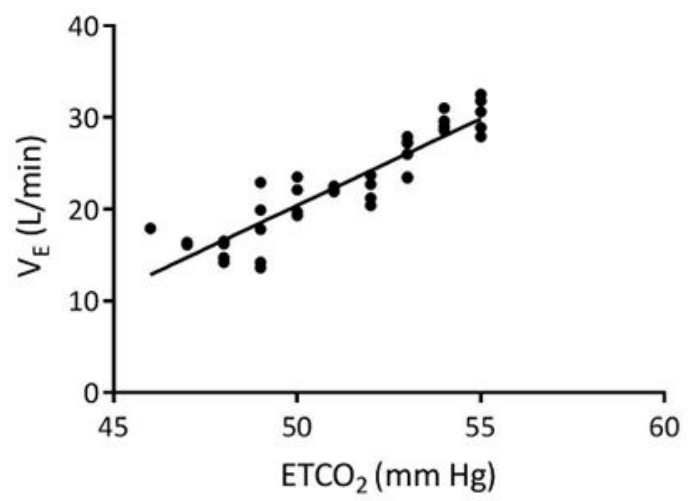

C) Subject with highest slope

Slope $=5.39 \mathrm{~L} / \mathrm{min} / \mathrm{mm} \mathrm{Hg}$

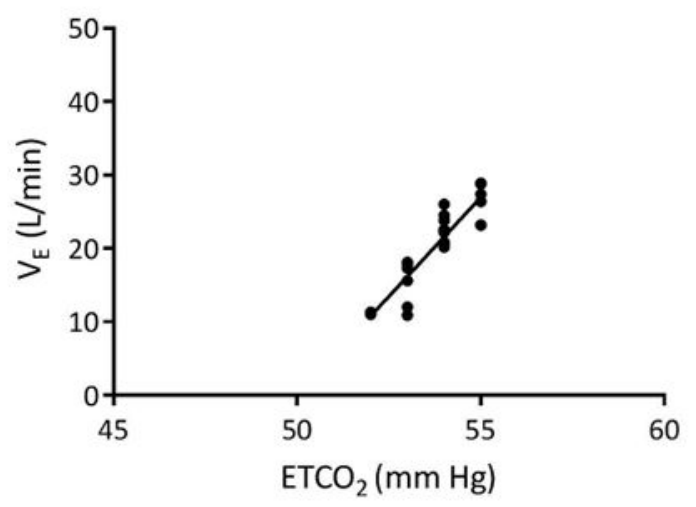

B) Subject died of SUDEP Plus

Slope $=0.19 \mathrm{~L} / \mathrm{min} / \mathrm{mm} \mathrm{Hg}$

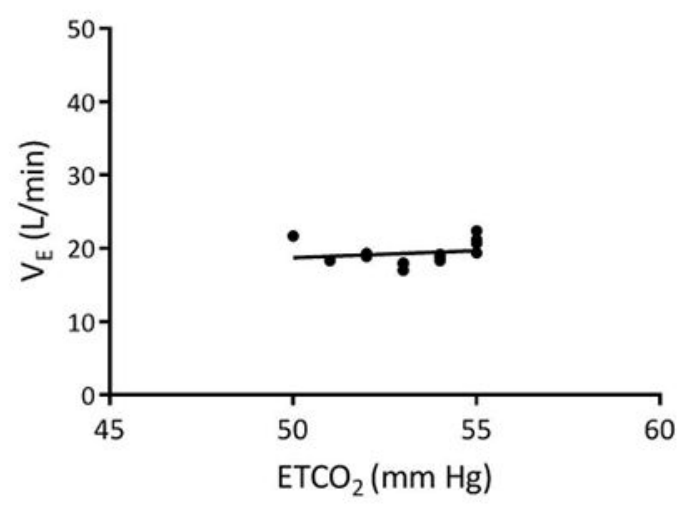

D) Frequency distribution of HCVR slope

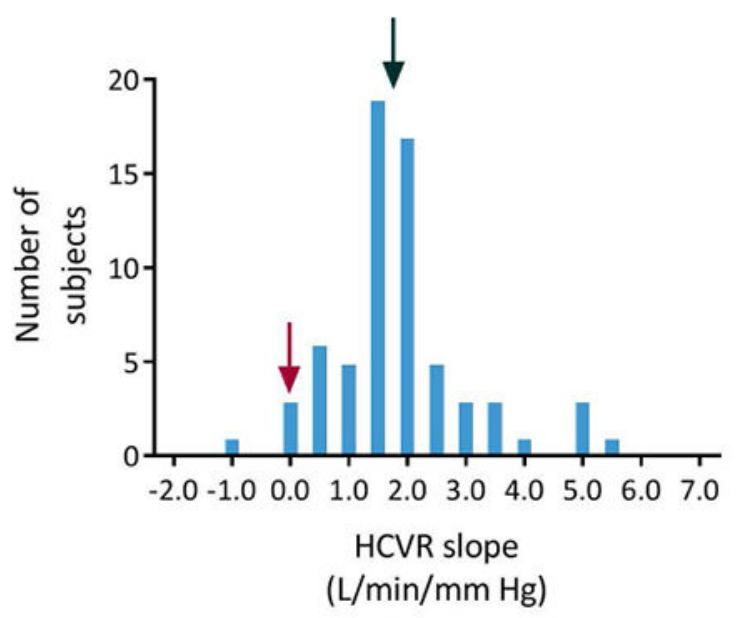

Figure 1:

Linear regression of $\mathrm{V}_{\mathrm{E}}$ and $\mathrm{ETCO}_{2}$ for (A) the subject with the median slope, (B) the subject who died of SUDEP plus, and (C) the subject with the highest slope. (D) shows the frequency distribution of HCVR slopes. The black arrow points to the subject with the median slope and the maroon arrow indicates the subject who died of SUDEP plus. 
A)

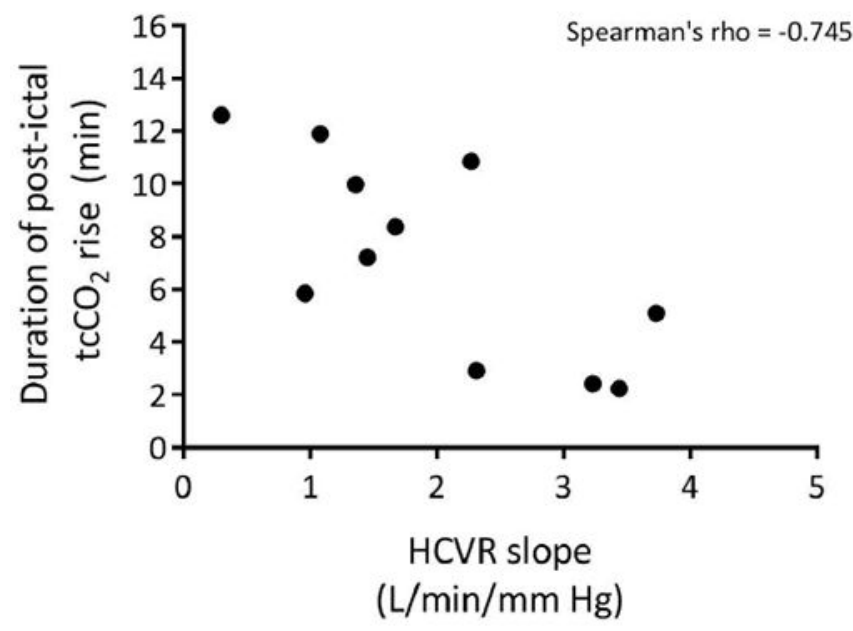

B)

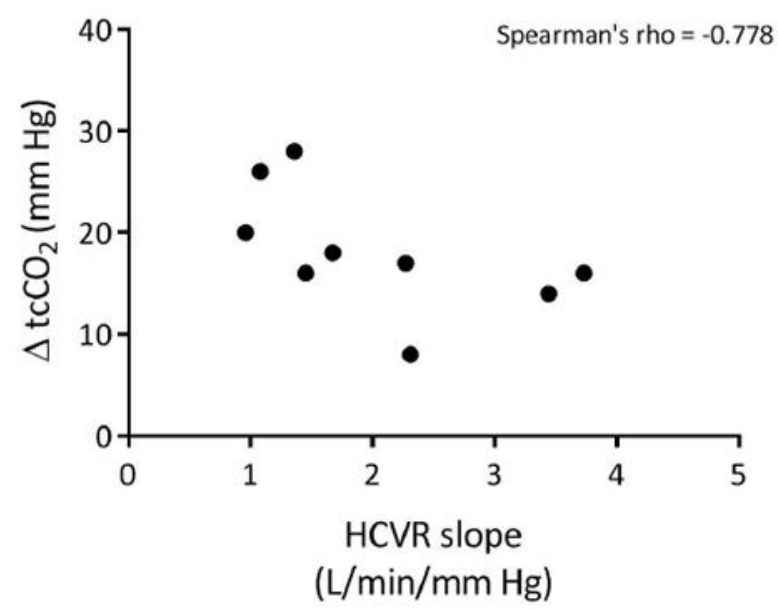

Figure 2:

Scatter plot depicting the correlation between HCVR slope and (A) duration of post-ictal tcCO ${ }_{2}$ rise and (B) magnitude $\left(\Delta t \mathrm{cCO}_{2}\right)$ of post-ictal tcCO $\mathrm{CO}_{2}$ rise. 


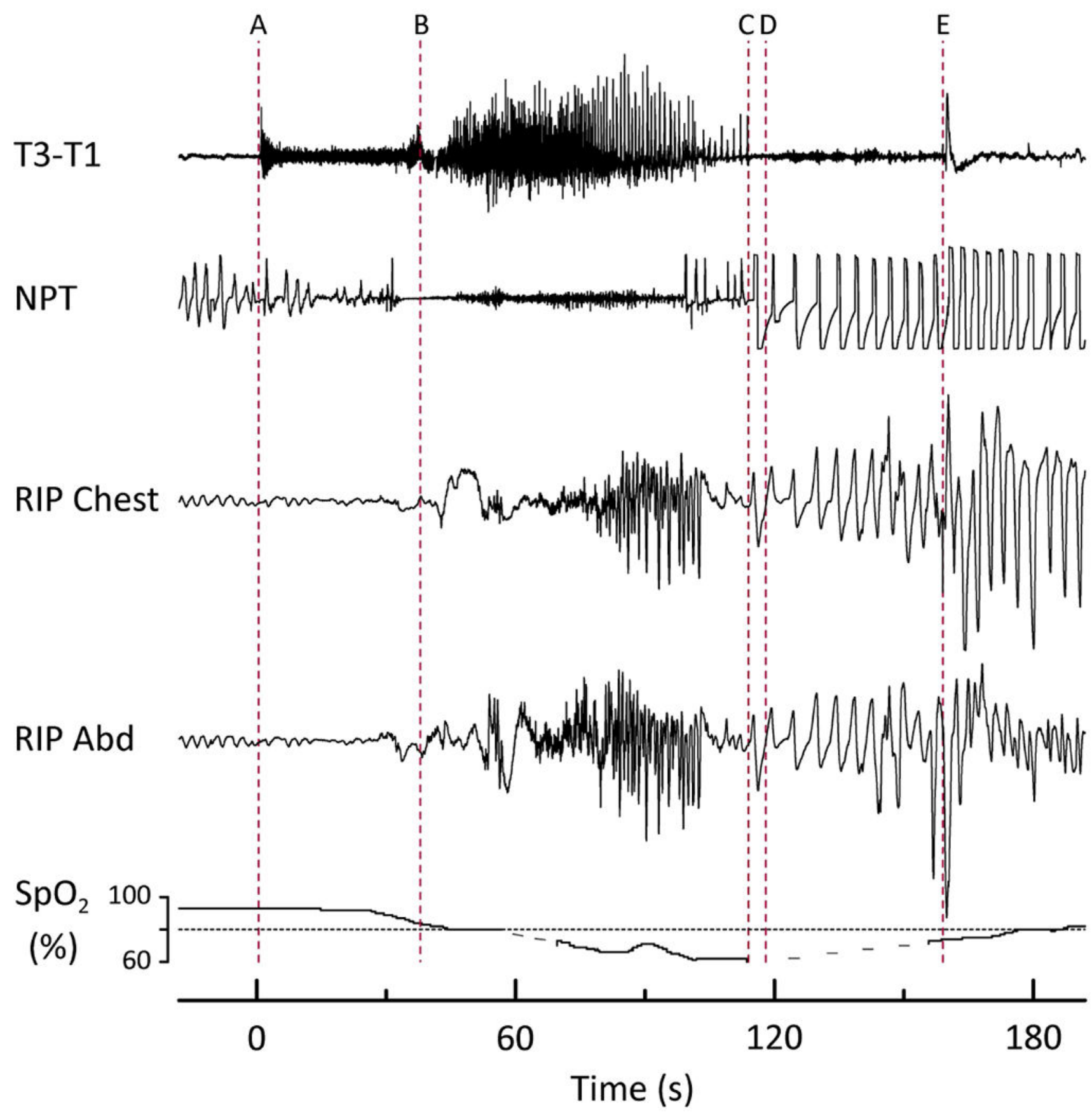

Figure 3:

Peri-ictal respiratory depression complicating a focal to bilateral tonic-clonic seizure in a patient who later died of SUDEP Plus. Prior to (A) the patient was drowsy, lying supine in bed. (A) Clinical seizure onset (time 0) characterized by arousal, increased muscle tone, and apnea/hypopnea. (B) Vocalization and beginning of tonic phase. (C) Breathing resumed, initially with an irregular pattern, followed by increasing rate, depth, and regularity. Inspiratory flow limitation was evident on the NPT tracing, and both inspiratory and expiratory upper airway sounds were audible. (D) EEG seizure termination. (E) Patient was 
turned on to his left side by EMU staff. The duration of peri-ictal hypoventilation totaled 80 seconds, with oxygen saturation falling to a nadir of $61 \%$. Heart rate (beats $/ \mathrm{min}$ ) increased throughout the event: (A) 96, (B) 108, (C) 114, (D) 120, (E) 144. Dashed lines in the pulse oximetry tracing represent data dropout from movement. T3, T1 = left mid- and anteriortemporal leads, respectively, NPT $=$ nasal pressure transducer (airflow), RIP Chest $=$ thoracic (chest) respiratory inductance plethysmography, RIP Abd = abdominal respiratory inductance plethysmography, $\mathrm{SpO}_{2}=$ oxygen saturation. 


\section{Table \# 1.}

\section{Clinical characteristics}

\begin{tabular}{|c|c|}
\hline & $N=67$ \\
\hline $\operatorname{Age}(\mathrm{yrs})^{* *}$ & $40.43 \pm 13.81$ \\
\hline Gender (women \%) & 49.25 \\
\hline $\mathrm{BMI}^{* *}$ & $30.44 \pm 7.37$ \\
\hline Depression $(\%)$ & 40.29 \\
\hline OSA $(\%)$ & 20.89 \\
\hline Use of SSRI/SNRI (\%) & 23.88 \\
\hline Current smoking $(\%)$ & 23.88 \\
\hline \multicolumn{2}{|l|}{ Epilepsy Type (\%) } \\
\hline Focal & 82.09 \\
\hline Genetic generalized & 13.43 \\
\hline Symptomatic generalized & 1.49 \\
\hline Unclear & 2.99 \\
\hline \multicolumn{2}{|l|}{ Seizure semiology $(\%)$} \\
\hline Focal aware-non-motor & 20.90 \\
\hline Focal aware-motor & 7.46 \\
\hline Focal with impaired awareness- motor onset & 22.39 \\
\hline Focal with impaired awareness- non motor onset & 23.89 \\
\hline Focal to bilateral tonic-clonic & 46.27 \\
\hline Generalized- motor onset & 7.46 \\
\hline Generalized- non motor onset & 1.49 \\
\hline Unknown onset & 7.46 \\
\hline Unclassified & 2.99 \\
\hline Duration of epilepsy $(\mathrm{yrs})^{* * *}$ & $17 \pm 14.11$ \\
\hline
\end{tabular}


Table \#2.

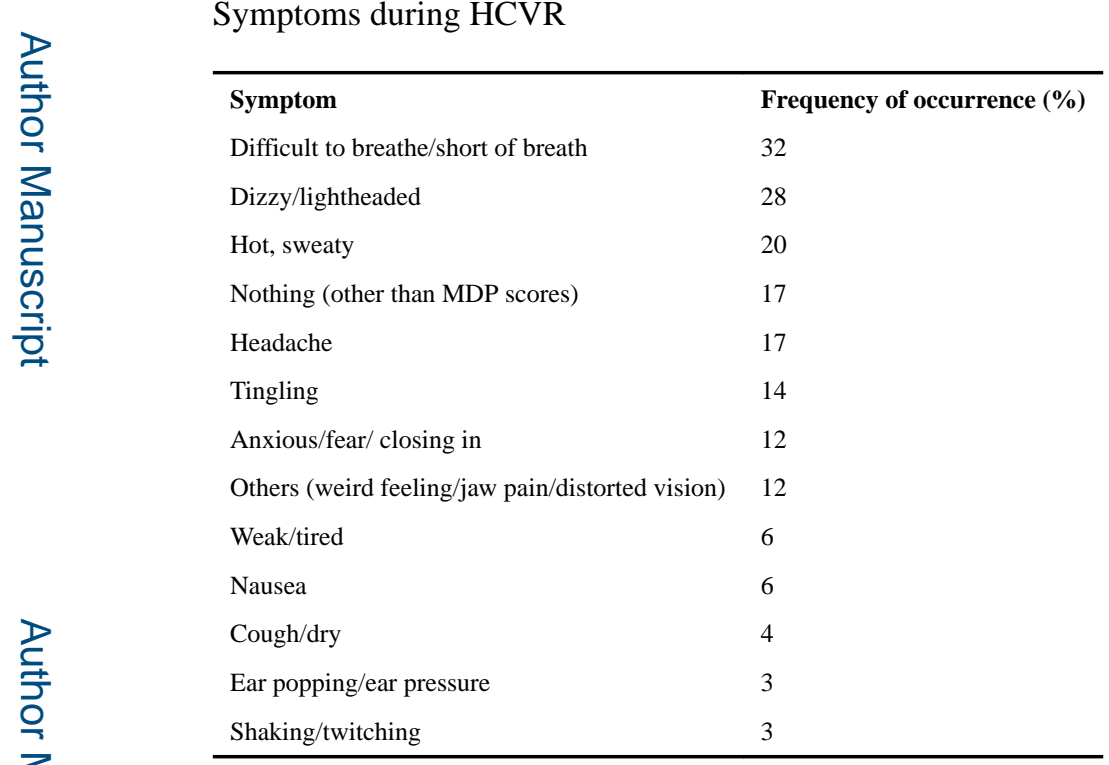


Table \# 3A.

The relationship between HCVR slope and selected clinical variables

\begin{tabular}{lll}
\hline & HCVR slope & \\
Independent variable & Spearman 's rho & $\mathbf{p}=$ \\
Age & -0.171 & 0.167 \\
Gender & 0.133 & 0.284 \\
Duration of epilepsy & -0.051 & 0.685 \\
BMI & 0.136 & 0.271 \\
SSRI/SNRI use & -0.016 & 0.896 \\
OSA & 0.039 & 0.756 \\
Curent smoking & 0.051 & 0.685 \\
Baseline ETCO 2 & -0.267 & $0.034^{*}$ \\
Unpleasantness of dyspnea & 0.434 & $0.0003 *$ \\
Intensity of dyspnea & 0.468 & $0.000085^{*}$ \\
\hline * $\leq 0.05$ & &
\end{tabular}

Abbreviations: BMI- Body mass index; OSA: obstructive sleep apnea; SSRI- selective serotonin reuptake inhibitor; SNRI- serotonin and norepinephrine reuptake inhibitors 
Table \# 3B.

Determinants of post-ictal hypercapnia

\begin{tabular}{|c|c|c|c|c|}
\hline & \multicolumn{2}{|c|}{ Duration of post-ictal $\mathrm{tcCO}_{2}$ rise } & \multicolumn{2}{|l|}{ Post-ictal $\Delta$ tcCO$_{2}$} \\
\hline & Spearman's rho & $\mathbf{p}=$ & Spearman's rho & $\mathbf{p}=$ \\
\hline BMI & -0.436 & 0.180 & -0.536 & 0.137 \\
\hline OSA & 0.224 & 0.509 & -0.206 & 0.594 \\
\hline Duration of convulsion & 0.082 & 0.811 & -0.218 & 0.574 \\
\hline Duration of peri-ictal $\mathrm{O}_{2}$ desaturation & 0.486 & 0.329 & 0.800 & 0.104 \\
\hline Nadir peri-ictal $\mathrm{SPO}_{2}$ & -0.395 & 0.309 & 0.193 & 0.647 \\
\hline HCVR Slope & -0.745 & $0.008^{* *}$ & -0.778 & $0.014^{* *}$ \\
\hline Post-ictal $\Delta \mathrm{tcCO}_{2}$ & 0.770 & $0.015^{* *}$ & NA & NA \\
\hline Duration of peri-ictal $\mathrm{tcCO}_{2}$ rise & NA & NA & 0.770 & $0.015^{* *}$ \\
\hline
\end{tabular}

Abbreviations: BMI- Body mass index; OSA- Obstructive sleep apnea 